\title{
HANDLING OF SYRINGE SHARPS IN A NON-INCINERATION HEALTH CARE WASTE DISPOSAL
}

\author{
Tito E. Mwinuka and Bavo B. Nyichomba \\ Department of Mechanical and Industrial Engineering, College of Engineering and \\ Technology, University of Dar es Salaam, P. O Box 35131, Dar es Salaam, Tanzania \\ Email:tmwinuka@udsm.ac.tz; nyichomba@udsm.ac.tz
}

\begin{abstract}
An attempt has been made by the $R \& D$ team of the University of Dar es Salaam to design and manufacture two needle cutter prototypes, a manually operated and an automatic needle cutter to be used in rural and urban areas, respectively. This is part of the UNDP and WHO efforts aimed at promoting the non-burn medical waste disposal technologies in developing countries such as Argentina, India, Latvia, Lebanon, Philippines, Senegal, Tanzania and Vietnam. The project also involves designing and manufacturing of the autoclaves for sterilizing of needle cutters and other infectious medical waste. The use of needle cutters in hospitals is aimed at cutting the needles off from syringes hence eliminating the possibility of being re-used as may be the case if they are just buried in landfills. The needles and plastic barrels of the syringes are then sterilized at $121^{\circ} \mathrm{C}$ in an autoclave before disposing them in land-fills or recycling them. It should be noted that unlike manual needle cutters, automatic needle cutters do not add a step in administering injection and hence they are likely to be accepted by nurses and health care authorities. Two types of automatic cutter prototypes were developed by UDSM R\&D Team; one using pneumatic mechanisms and the other one using a $12 \mathrm{~V}$ DC motor to cut the syringe needles and to push the plastic barrel into the waste container. Of the two, the 12V-DC motor operated mechanism was found to be affordable and suitable for use in rural areas also since it can easily use solar power. The above prototypes have already been manufactured and tested and found to be working properly. Views of various stakeholders were used to improve and perfect the designs. The costs of these prototypes are estimated to be USD 50 and 150 for manually operated needle cutter and 12V-DC operated needle cutter, respectively. These technologies, except the automatic needle cutters, have already been disseminated to local producers so as to be able to manufacture the same in mass production and at much more affordable costs. Training on the use of non-burn technologies including management of medical waste is essential for successful implementation of these technologies. There is a need also to sensitize the Government, Municipal Authorities and Healthcare Authorities including hospitals on non-burn disposal of medical waste for the project to be successful.
\end{abstract}

Keywords: Automatic needle cutter, Hospital waste disposal, Hospital waste recycling, Non-incineration waste disposal, Syringe needle cutters. 


\section{INTRODUCTION}

The design and manufacture of the needle cutter equipment is part of the efforts by UNDP and WHO in promoting the best techniques and practices for reducing health care hazards arising from handling of syringes in hospitals after the injection. Sharps and more specifically syringes are considered the most hazardous category of health care waste for health care workers and the community at large (WHO, 2006). The common practice of handling syringes after injection has been that of collecting the used syringes in yellow safety boxes or other types of bins and either burning, incinerating or burrying the same in the land fills without proper treatment (SBC and WHO, 2004)

It is well known that one of the challenges facing a number of hospitals in developing countries like Tanzania is how syringes should be handled and treated after injection so as to ensure that they do not cause injuries and infenctions to health care workers, patients and people who scavenge through the municipal and medical wastes. Another challenge is that of introducing a new practice of cutting sharps from syringes before the same are autoclaved and then shredded before their disposal. It is important to note that preliminary surveys (WHO, 2004) have shown that introducing a syringe cutter is considered by health care workers as an additional step in their work. These people are used to the practice of throwing the syringes in the bin after injection and not otherwise. Thus, any procedure other than that is likely to face resistance from healthcare workers (Stringer et al., (2010), Developing countries are lacking proper resources to collect and manage sharps waste appropriately and therefore have higher rates of needle-stick injuries which ranges from 0.93 to 4.68 injuries per person per year compared to from 0.18 to 0.74 injuries per person per year in developed countries (WHO, 2006).

Pursuant to the above, the R\&D Team of the University of Dar es Salaam was nominated to participate in the project to demonstrate and promote the best techniques and practices for reducing health care waste risks such as those caused by injection syringes. It is envisaged that the best practices that would be developed would be shared by eight countries namely; Argentina, India, Latvia, Lebanon, Philippines, Senegal, Tanzania and Vietnam. The Tanzania component was mainly to undertake a component of developing, testing and disseminating the technology for handling injection syringes before their disposal in the above developing countries. The Project is funded by the Global Environmental Facility (GEF) through UNDP and working closely with WHO and Health Care Without Harm (HCWH).

This paper therefore concentrates on development of the prototypes for handling syringes after injection including engineering designs, standardization, fabrication, and documentation for syringe needle cutters including prototype testing both in-house and extensive field tests with necessary refinements, test protocols and manuals. In addition, the paper covers technology transfer and dissemination of the technologies developed to the already earmarked developing countries.

\section{PREVIOUS WORKS}

\section{Surveyed Needle Cutters/Destroyers in the Market}

There are several types of needle cutters that are in the market that are at disposal for usage by the health care authorities. Some of the surveyed needle cutters that are readily avaible in the market include: 
manually operated needle cutter using the scissor mechanism, the balcan type needle cutter, electric needle destroyer and plastic shredding machine and are briefly explained below.

\section{(a) Scissor Type Needle Cutter}

This type of needle cutter consists of a scissor mechanism fixed at the top cover of the needle cutter (Figure 2.1). This top cover also has a hole where the syringe is inserted before the whole process of cutting off the needle sharp. The cutting process starts by inserting the needle into the top cover hole where the needle sharp is cut by rotating one scissor handle containing the cutting blade which in turn shears the needle hub against the other fixed blade of the scissor. As the two parts of the scissor blades shear the needle from the syringe, the sheared needle sharp falls into a plastic container. The process of cutting the sharps from the syringes continues until when the plastic container is full after which it is removed for further processing (sterilizing) of the sharps before being disposed off.

\section{(b) Balcan Neeldle Cutter}

As seen in Figure $2.2 \mathrm{a}$ and $\mathrm{b}$, this type of syringe needle cutter consists of two concentric cylinders, the inner and the outer which are used as the cutting tools for the needle sharps. The inner cylinder is made to rotate inside the outer cylinder by turning the handle attached to the inner cylinder. Both cylinders have radial through holes into which the needle is inserted. The cutting process starts by rotating the inner cylinder against the stationary outer. This, in turn, causes the needle sharp which is held between the two holes of the inner and outer cyliders to be sheared off in two pieces. The needle sharp pieces are made to fall into a removable container and the container is empted when it is full ready for sterilization.

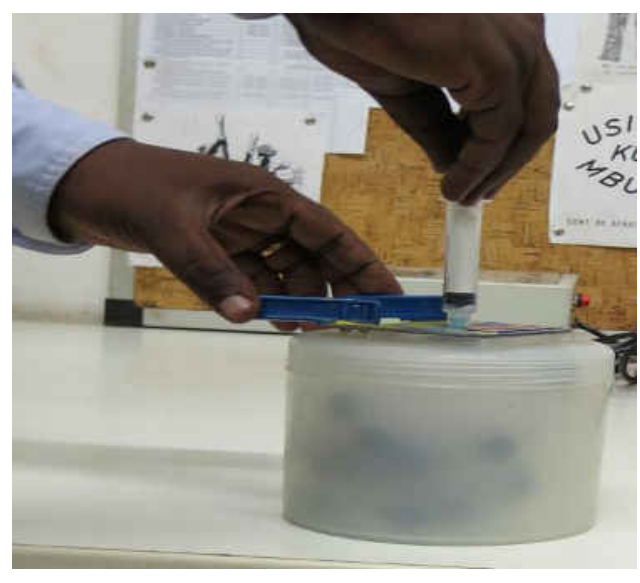

Fig. 2.1a: Manual needle cutter using scissor mechanism

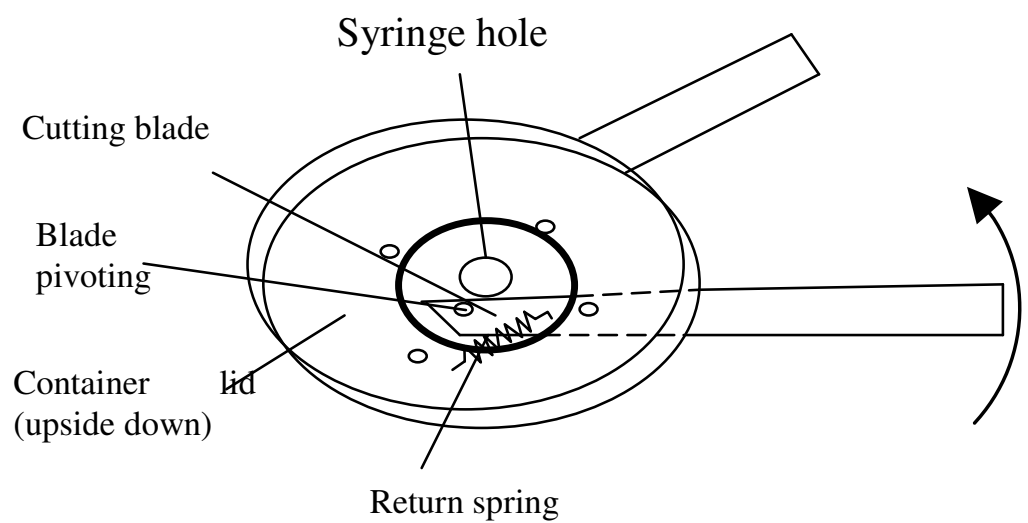

Figure 2.1b: Schematic Diagram of Scissor Mechanism 


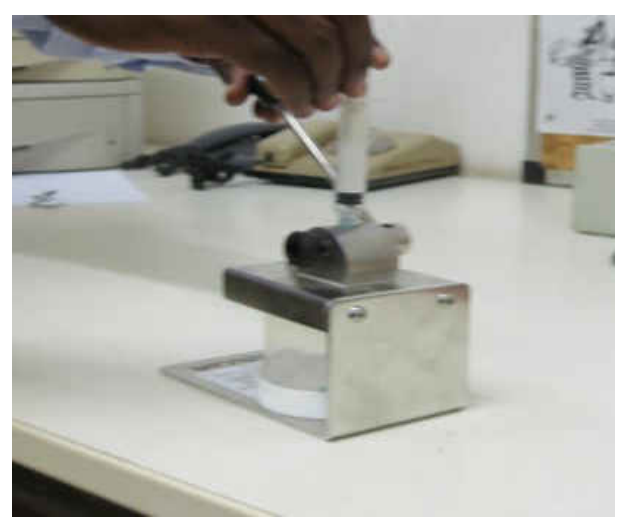

Figure 2.2a: Balcan needle cutter

\section{(c) Electric Needle Destroyer}

This type of needle cutter as seen in Figure $2.3 \mathrm{a}$ and $\mathrm{b}$ uses electric arc to melt the needle once it is inserted into the equipment. After the needle is melted (vaporized), the hub is cut using scissor like mechanism and the plastic part thrown into the container ready for further recycling process. One of

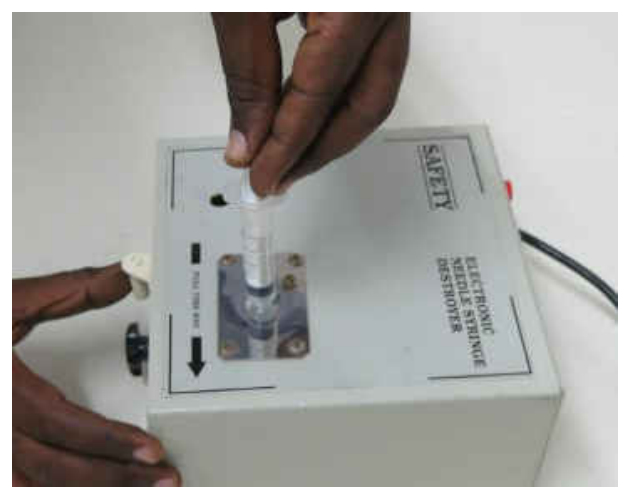

Figure 2.3a: Electric arc Needle destroyer

\section{Observed Shortcoming of the Needle Cutters in the Market}

Although there exists a number of needle cutters in the market for health care use

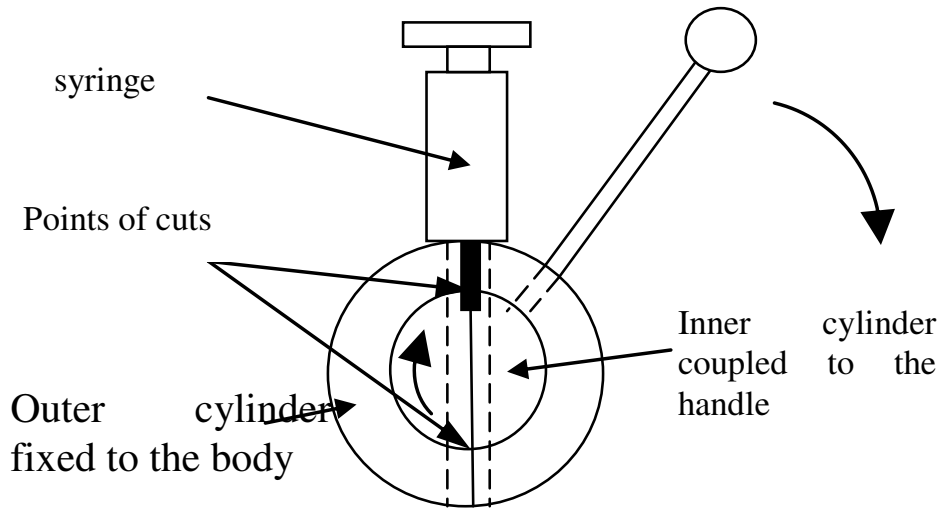

Figure 2.2b: Schematic diagram of the Balcan needle cutter mechanisms

the concerns of this type of approach is that it produces vapours from the melted needle sharps as well as from part of the plastic materials meant to hold the needles in the syringes. It is envisaged that these vapours might be harmful and hence there is need to investigate whether the produced vapours are safe for the operators or not.

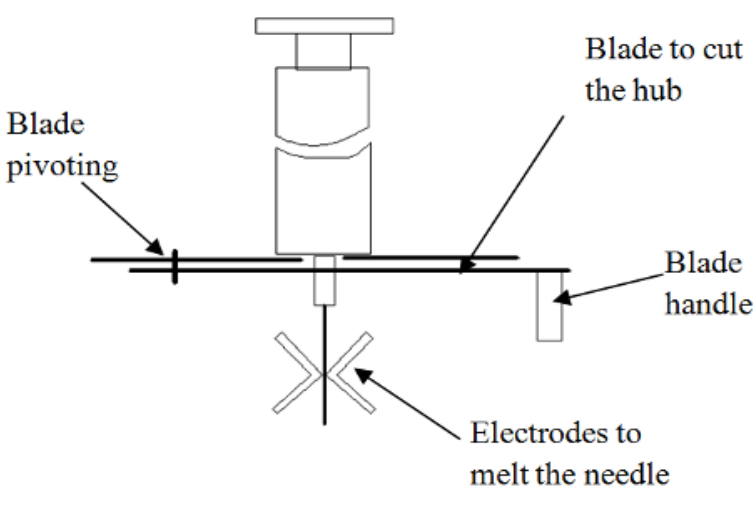

Figure 2.3 b: Schematic diag. of the electric arc needle destroyer

world-wide, most of the hospitals seem to have little interest in using this kind of technologies. This is especially true with nurses who are responsible for injection of patients in hospitals. The reasons for non use 
of needle cutters is that they tend to add additional steps to the injection operations as it will involve the nurse moving with the syringe from a point of injection to the needle cutter, placing the syringe in needle cutter and operating the needle cutter to get rid of the sharp before throwing the plastic part of the syringe into the required waste box. The above practice has been observed to be time consuming and is risky to healthcare workers as it may cause unnecessary injuries to other workers in the course of the nurse moving with a syringe from one point to another. The practice is also tiresome to nurses as it involves maximum concentration in following up the right procedures each time she/he injects a patient.

In summary, destruction of syringes after their use is necessary to implement a nonburn health care waste disposal practice. However, needle cutters available in the market are manually oparated and thus add a step in health care operations and it also risky to health care workers.

\section{Present Study}

It should be noted that nurses are used/trained to the injection procedure of injecting and dropping the whole syringe into the medical waste box. Any step apart from that, to them is an extra work. Thus, the only technology that is likely to be accepted by health workers is that which will not add any step to what they are used to.

To ensure that there will be no additional step as currently practiced by health care workers, it was necessary therefore to come up with a needle cutter design concept that will require the health workers to continue with their practice of dropping the used syringes in the same way they are used to drop into yellow sharp boxes. In this case, there is need to have the mechanism in place that will cut needle from the plastic part and that will separate sharps from plastic materials of the syringes for recycling purposes. In this case there will be no additional step that will be experienced by the nurses.

However, in order to design such an equipment or mechanism there is a need to abide to specified criteria by WHO (2009) which are used for manufacturing of needle cutters for healthcare. These include; performance, environmental requirements, physical characteristics, interface requirements, human factors, materials, servicing provisions and disposal and recycling.

\section{RESEARCH METHODOLOGY}

In order to carry out the assignment as stipulated above, the following methodology was used:

(a) Review of literature and various relevant documents with regard to medical waste management: This involved identification, collection and review of documents, available data and information relevant to the assignment.

(b) Field Studies: Field studies entailed meetings, consultations and interviews with various stakeholders both internally and externally. Since the concept of non-burn of health care wastes was new in this country and other developing countries, members of the R\&D group at the University of Dar es Salaam visited a number of industries in India dealing with waste disposals using non-burn technologies so as to get acquainted with the best technologies and practices that were to be adopted by the project members in their design, test and manufacture. 
Based on the analysis of findings from literature review as well as from field studies, it was possible to establish facts about design attributes that need to be considered in order to come up with a suitable design of the needle cutter. The group established evaluation matrix to evaluate different design alternatives in terms of how best they conformed to preset specifications. The major attributes included in the design selection matrix were factors such as power source, capacity, materials, manufacturability, and convenience of using, safety, cost and serviceability.

(c) Stakeholders Workshops: To perfect the generated design concepts of needle cutters, it was necessary to subject them to a wide scrutiny in various stakeholders' workshops with a view to ensuring acceptability, suitability and ownership of the same. The following selected key and representative stakeholders were invited to the workshops conducted by the $R \& D$ Team of the University of Dar es Salaam:

(i) UNDP/GEF Coordinator Health Care Waste Project;

(ii) UNDP/GEF consultants/Technical Advisors (Resource Persons);

(iii) Environmental Engineers, Medical Officers, Human doctors from hospitals in Dar es Salaam and related institutions;

(iv) University of Dar es Salaam staff and students doing environmental studies.

The purposes of the workshops were to confirm and/or enrich the Team's conceptual designs of needle cutters for developing countries. Through the inclusion of various stakeholders' ideas, the designs and hence the prototypes developed were perfected.

\section{RESULTS AND DISCUSSION}

\section{Conceptual Design of Needle Cutters}

In order to ensure that designing and manufacturing of the non-burn healthcare waste disposal technologies in Tanzania was according to the set WHO criteria, a special committee namely Technology Development Advisory Committee (TDAC) was involved fully in overseeing the designing of the technologies developed by the UDSM R\&D Team. The criteria used for designing the non-burn technologies such as the needle cutter include the following:

Portability: The needle cutter should be portable and easily movable around hospital premises.

Skill requirement: No specialized skill is needed to be able to operate the equipment. The user should only be able to read.

Power source: The equipment should not require grid electricity so that it can suit both rural and urban environment.

Capacity: The equipment should be able to cut more than 1,000 needles before the need for emptying or servicing.

Safety: The needle cutter should pose minimum safety risk to the operator. Additional step(s) in health care operations should be avoided.

Manufacturability: It should be possible to manufacture the equipment in local workshops. No specialized processes shall be needed.

Cost: The needle cutter should be cheap, if possible should cost less than USD 1

\section{Design Concepts}

A number of possible design alternatives were conceptualized and assessed using the already stated WHO criteria. However, only two types of needle cutters were observed to satisfy the stipulated WHO criteria as 
explained in Section 4.1. These are manual needle cutter and automatic needle cutter designs.

\section{Manual Needle Cutter}

A manual needle cutter was designed to work in a similar manner as a scissor but in this case, the container for receiving barrels was directly attached to the unit. However, a separate container may be used. The second option made the design to be smaller and portable. Both needles' and barrels' containers are designed in such a way that they can be removed for emptying.

\section{(a) Working principles}

The top cover was designed in such a way that it shall have a hopper, a hole to insert the needle hub and a handle for cutting the syringe (Figure 4.1). The hopper is introduced in this design to guide the syringe and protect the user from droplets since the use of needle cutters can be associated with release of droplets of blood to the surroundings which may be infectious (Binley et al., 1984).

The cutting mechanism was attached to a tension spring which returns the handle to its original position after cutting. The inner container that stores the sharps (cut needles) shall have the top cover which can be opened to empty the container when full. The top cover has an opening with spring loaded sliding lid. The sliding lid is triggered to open up only when the container is inserted into the syringe cutter housing. The inner container that accommodates the sharps was designed in such a way that all the sharps will be intact inside it in case it falls down and hence protect people from injury and infections. Figure 4.2 shows the process of insertion and locking up the needle container into the needle cutter.

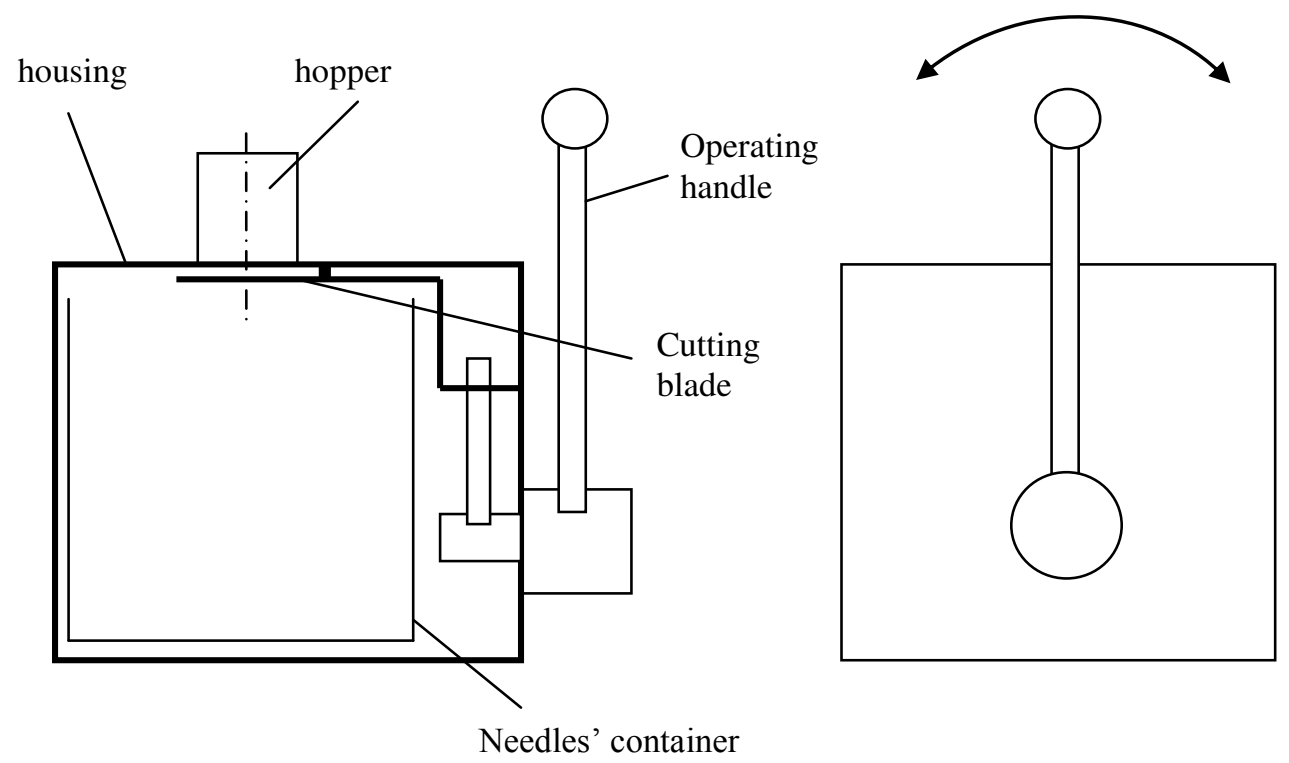

Figure 4.1: Working principle of a manual needle cutter 


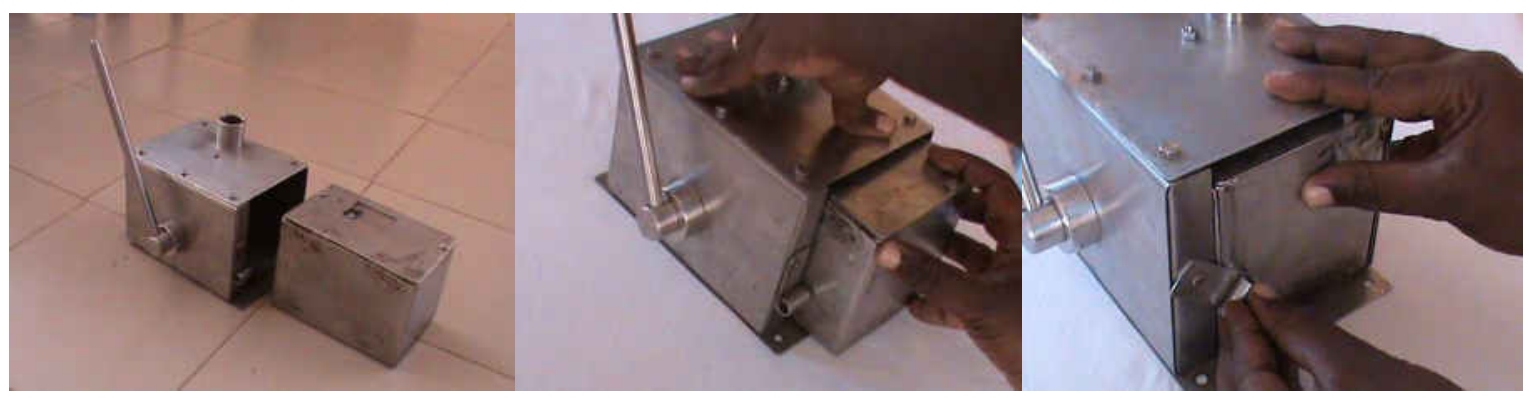

Figure 4.2: Insertion and locking up the needle container

\section{(b) Test results}

Tests with the manual needle cutter have shown that the syringe can successfully be cut using reasonable force. To a much extent, the design was acceptable by stakeholders. However, a number of stakeholders observed that the size of the needle cutter needed to be reduced further up to $50 \%$ keeping the handle size the same. This would help to increase portability of the equipment. The other problem observed is that nurses would be reluctant to use the equipment since the whole idea of introducing the manual cutter tends to complicate their work as it adds up an additional step onto what they are used to.

\section{Automatic needle cutter}

This design was conceptualized from the fact that it accommodates the current practice of handling used syringes of dropping them into yellow sharp boxes thereby eliminating additional step during the injection operations. Under this category, two concepts were developed and tested. These are Pneumatic Operated Needle Cutter Design and DC motor operated needle cutter.

\section{Pneumatic operated needle cutter design}

\section{(a) Working Principle}

This concept of automatic needle cutter is as seen in Figure 4.3 and it consists of the following:

(i) A hopper to receive the syringes;

(ii) A photo sensor to detect the presence of a syringe;

(iii) A cutting blade coupled to a pneumatic cylinder for cutting off the syringe at the hub;

(iv) A movable hopper coupled to another pneumatic cylinder to push the remaining barrel into the barrel container;

(v) The equipment also contains a smaller container for receiving and storing the needles. Both containers are removable for emptying.

(vi) An electric compressor is used to supply the pressurized air for the pneumatic cylinders.

(vii) Overall dimensions of the developed prototype are $400 \mathrm{~mm}$ x $300 \mathrm{~mm}$ $\mathrm{x} 1000 \mathrm{~mm}$.

This design involves a sharp metal blade attached to a pneumatically operated cylinder which is designed to move linearly back and forth as seen in the schematic diagram of the equipment, Figure 4.3a. The forward motion of the pneumatic cylinder is triggered by a sensor when the syringe is thrown into the 
hopper by the health worker. As the pneumatic cylinder No. 1 moves forward, the shearing blade attached to it in turn cuts off the syringe needle or sharp. As the sharp drops into container No. 1 , the pneumatic cylinder moves backward triggering another sensor that operates the second pneumatic cylinder (No. 2) to push the plastic part of the cylinder into another container (No. 2) and the cycle repeats as another syringe is thrown into the hopper. Pneumatic and electric circuits are shown in Figures $4.3 \mathrm{~b}$ and $4.3 \mathrm{c}$ respectively. Note that the hopper is designed in such a way that it will guide syringes to stay in their upright position.

One of the disadvantages of this design concept is that it is unnecessarily costly due to the use of the compressor, two pneumatic cylinders and other electrical gadgets. The use of electricity is another disadvantage of this concept as it cannot be used in most of the rural areas. Also, maintenance costs add up to the disadvantages of this concept. These sentiments were also shared by the stakeholders' workshop in May 2012. A number of concerns were raised by the stakeholders on the pneumatically operated needle cutter. They included:

(i) The prototype was rather big unnecessarily;

(ii) The prototype was not portable enough to be taken around the wards and could better be positioned in the Out Patient Department (OPD) injection room;

(iii) It was found to be unsuitable for rural applications as it needed electricity.

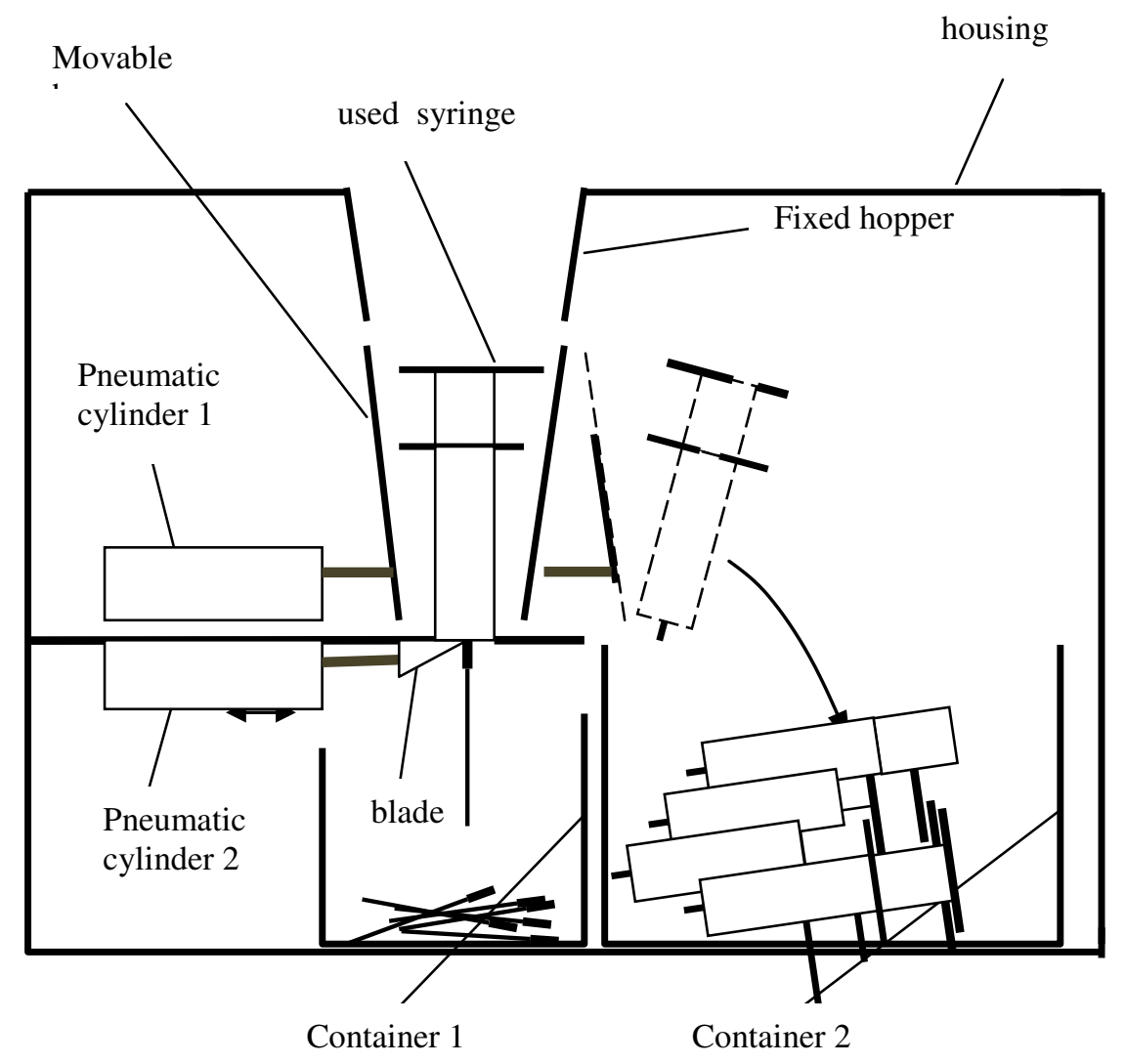

Figure 4.3a: Working principle of pneumatically operated automatic syringe cutter 


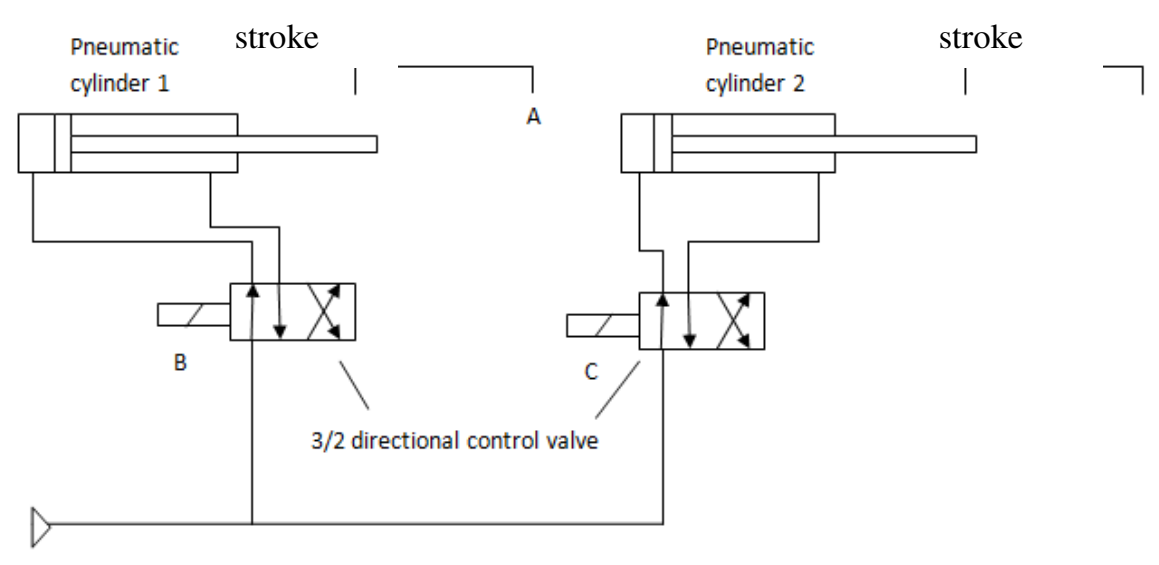

Figure 4.3b: Pneumatic circuit of an automatic needle cutter

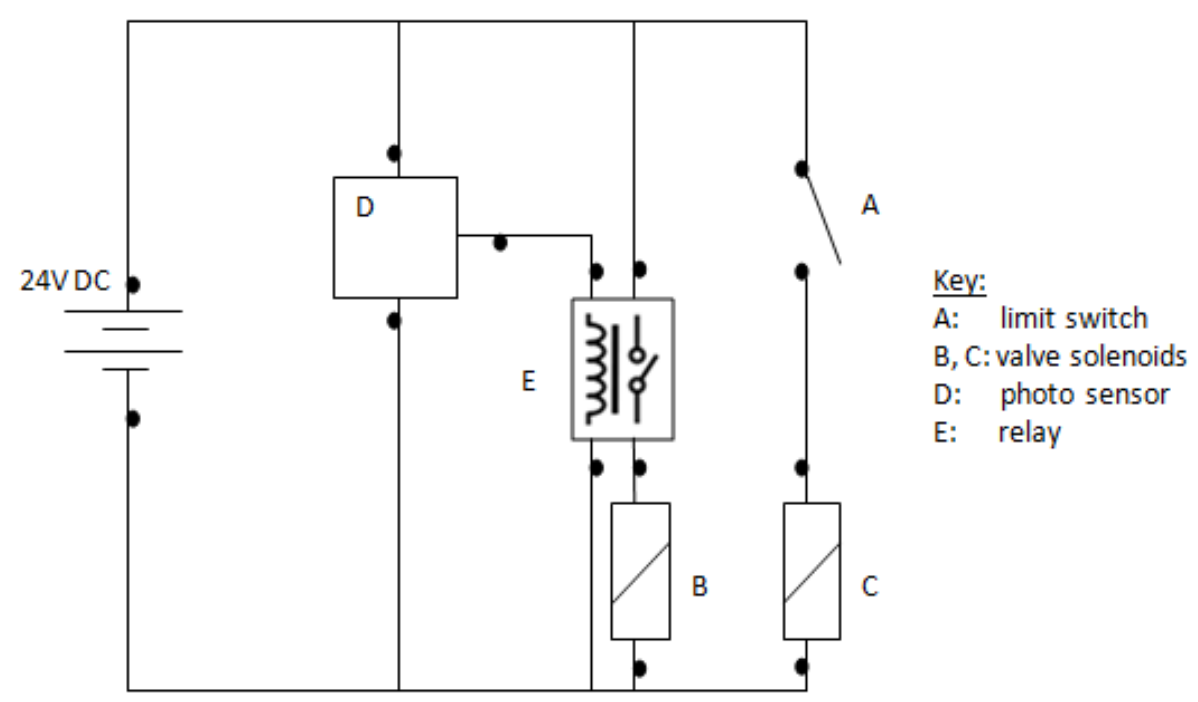

Figure 4.3c: An electric circuit for an automatic needle cutter

\section{Motor operated needle cutter}

\section{(a) Working Principle}

This design concept was developed following the shortcomings observed on the pneumatically operated needle cutter design discussed in 4.2.2a. The said shortcomings included, among other things, high costs of the air compressor needed to provide pressurized air to the two pneumatic cylinders, one for the cutter and one for pushing the plastic barrel of the syringe into the waste container. Pursuant to the above, this design of the needle cutter system was conceived to operate in the same manner as the one using pneumatic cylinders except that; in this case the pneumatic cylinders were replaced by $12 \mathrm{~V}$-DC motors with a spur gear to drive a rack linearly forward and back as seen in Figure 4.4. The rack is coupled to the cutting blade at its front end. By so doing, the blade cuts the syringe sharps which end up falling into the container. The design includes a photo sensor to detect the presence of syringe once thrown in the hopper and it sends the electrical signals to the $12 \mathrm{~V}-\mathrm{DC}$ motor to 
drive the rack shaft/knife forward to shear off the syringe needle.

In summary, the design consists of (i) a hopper to receive used syringes; (ii) a cutting blade mounted to linearly moving rack; (iii) a geared $12 \mathrm{~V}$ DC motor with a pinion on its output shaft; (iv) a photo sensor to detect the presence of syringe; (v) a fork to lift the cut syringe out of the hopper; (vi) container to receive needles; (vii) container to receive barrels and (viii) a $12 \mathrm{~V}$ power supply.

One of the advantages of this concept against the one using pneumatic cylinders is that of using DC electricity and thus gives the possibilities of solar panels and battery which is ideal for rural applications. The power and control functions for forward and reverse motions of a DC motor are shown in Figure 4.6. Also, the prototype was designed to be compact, i.e. $200 \mathrm{~mm}$ x $200 \mathrm{~mm}$ x 300 $\mathrm{mm}$, and can be placed on a trolley so as to assist health workers moving with it from one patient room to another.

The ejection of the barrel after cutting is achieved by release tension of a shaped spring wire (Figure 4.5). The shaped spring wire is held down under tension by means of a hook which is attached to the rack. As the hook travels forward with the rack it reaches a point where, the wire is released from the downward force and in return it pushes up a fork where the barrel is supported and as such suddenly the barrel is thrown into the container. In Figure 4.5, the dotted line indicates the movement of spring wire and the barrel supporting fork during ejection.

The circuit works like this; when there is no syringe in the hopper the sensor switch is open (Normally Open Proximity Sensor), the circuit for the relay 3 is open and hence the circuit which is complete is the one responsible for returning the motor and rack to home position.

When the syringe is in the hopper, sensor switch is closed allows $24 \mathrm{~V}$ DC to energize relay 3 and, closing the circuit of relay 2 . When relay 2 is energized, $+12 \mathrm{~V}$ DC is supplied to the motor and hence the motor rotates clockwise causing the rack to move forward releasing the limit switch. When the limit switch is released the negative terminal of the motor is connected to the positive terminal of the $12 \mathrm{~V}$ supply.

When the syringe barrel is already ejected to the container, the sensor now cuts the supply to the relay 3 causing relay1 coil to energize, the negative terminal of the supply is connected to positive motor terminal and hence the motor receives $-12 \mathrm{~V}$ DC supply and rotates anticlockwise returning the rack to home position. The cycle restarts when there is a syringe in the hopper.

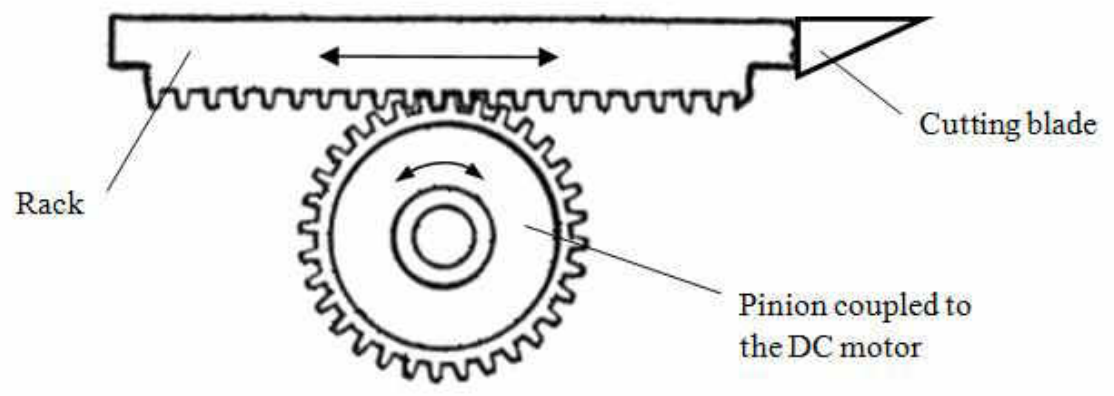

Figure 4.4: Pinion-rack mechanism 


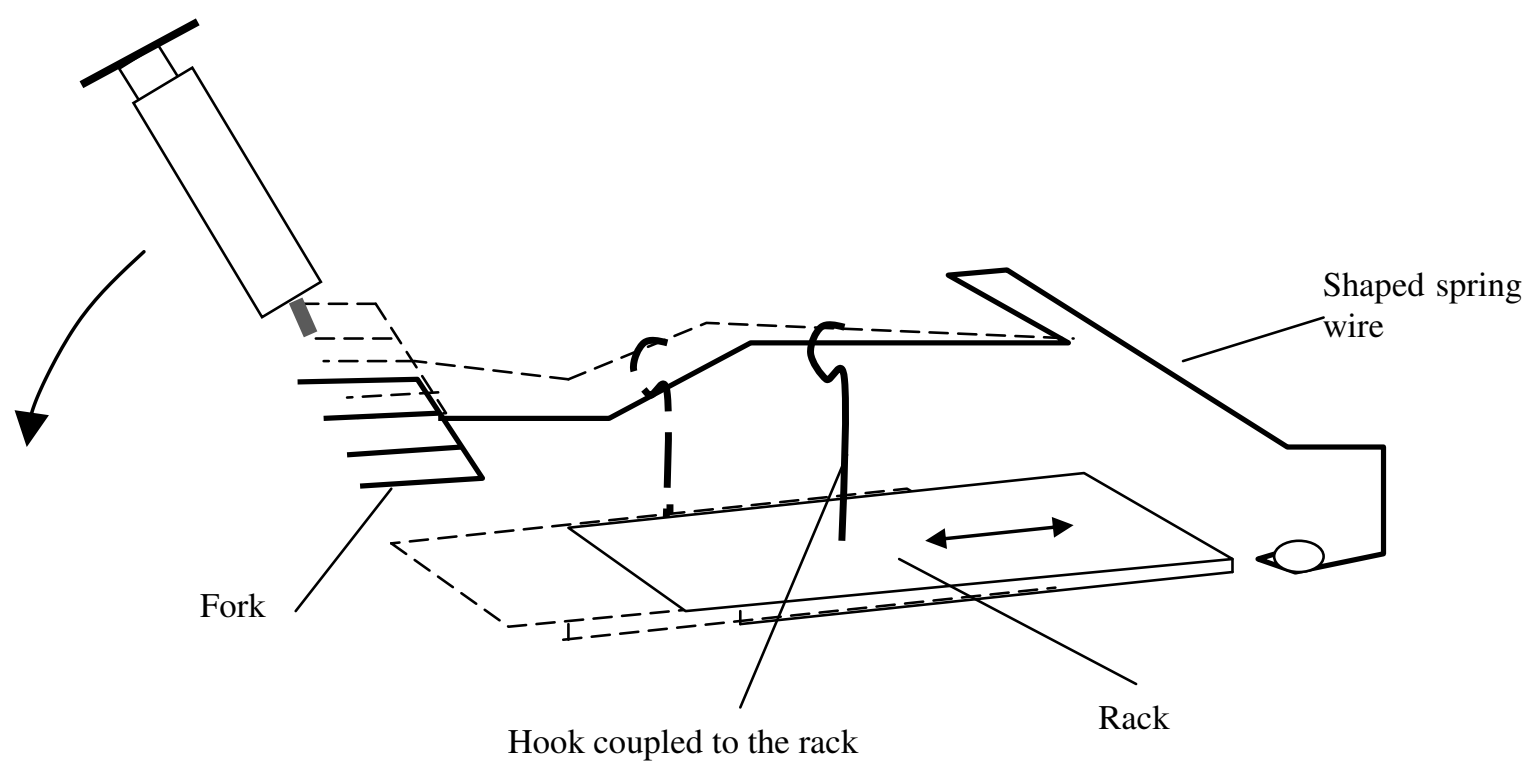

Figure 4.5: A mechanism for ejecting barrels

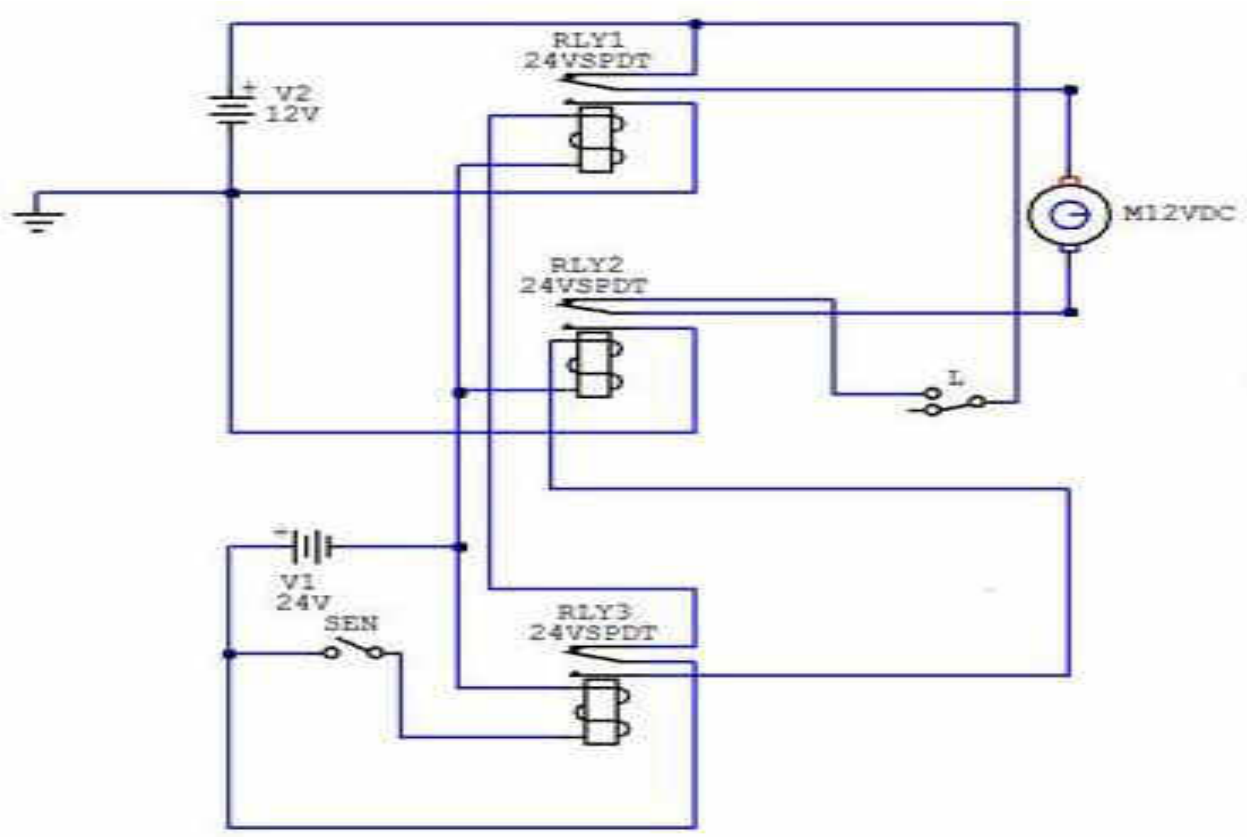

Figure 4.6: Power and Control circuit for an automatic needle cutter

\section{CONCLUSIONS}

From what has been achieved so far in this project, it can be concluded that;
1. The above mentioned needle cutter prototypes were designed, manufactured and tested. In principle, the 3 built prototypes that are the manually operated needle cutter and the 
automatically operated needle cutters both pneumatically and DC motor operated proved that the concepts are working. However, the DC operated needle cutter has not been perfected in its ejection mechanism.

2. Manual needle cutters, though they add a step in administering injections, they are cheaper in price and suitable for rural areas where there is no electricity.

3. Automatic needle destroyer is the most promising as it does not call for a change in the current practice of administering injections by healthcare workers.

4. Not all components of an automatic needle cutter can be manufactured fully by most of the earmarked manufacturing firms in Tanzania and this makes it difficult to keep costs down since the cost of electric/electronic gadgets dictate the overall cost of the equipment.

\section{RECOMMENDATIONS}

For future work, it is recommended that;

1. More work need be done especially for the DC operated needle cutter so as to perfect its ejection mechanism.

2. There is need to design a solar system that will be used to provide electricity for the DC operated cutter so as to make it viable for usage in rural areas.

3. Training on the use of non-burn healthcare waste disposal technologies including management of medical waste is essential for successful implementation of these technologies.

4. There is a need also to sensitize the Government, municipal authorities and health care authorities including hospitals on non-burn technologies for disposal of medical waste for the project to be successful.

5. These technologies need to be disseminated to more local producers so as to be able to manufacture the same in mass production and at much affordable costs.

\section{ACKNOWLEDGEMENTS}

Thanks to United Nations Development Program (UNDP) and Global Environmental Facility (GEF) for Funding the Project.

\section{REFERENCES}

WHO (2006). Management of waste from injection activities at district level: Guidelines for District Health Managers.

SBC and WHO (2004). Preparation of National Health-Care Waste Management Plans in Sub-Saharan Countries Guidance Manual.

Stringer R., Kiama J., Emmanuel J., Chenya E., Katima J. and Magoma F. (2010). Non-Incineration Medical Waste Treatment Pilot Project at Bagamoyo District Hospital, Tanzania: Project Report.

WHO (2009). PQS performance specification WHO/PQS/E10/NC01.1, Needle cutter for health waste management.

WHO (2004). Proposed Agenda to Evaluate the risks and benefits associated with using needle-removing devices. WHO/EHT/04.10.

Binley R.J., Fleming O.D., Swift D.L. and Tepper B.S. (1984). Release of Residual Material during needle cutting. American Journal of Infection Control, 12(5): 282288. 